\title{
Pulmonary involvement in primary biliary cirrhosis
}

\author{
R RODRIGUEZ-ROISIN, A PARES, M BRUGUERA, J COLL, C PICADO, A AGUSTI-VIDAL, \\ F BURGOS, AND J RODES
}

From the Pneumology and Liver Units, Department of Internal Medicine, Hospital Clinic i Provincial, Facultat de Medicina, Barcelona, Spain

ABSTRACT The association of pulmonary fibrosis and primary biliary cirrhosis (PBC) remains controversial. To determine the frequency of pulmonary fibrosis in $\mathrm{PBC}$, a carefully selected series of 14 PBC patients, seven patients with Sicca complex, and 14 control subjects have been studied. Seven $\infty$ of the 14 patients with PBC had Sjögren's syndrome, four of whom had some clinical evidence of pulmonary disease. Evaluation of ventilatory capacity, gas transfer factor, arterial blood gases, and lung mechanics were performed. Gas transfer was reduced in patients with PBC associated with Sjögren's syndrome and in patients with the Sicca complex. These results suggest that the respiratory, clinical, and functional abnormalities found in PBC are related to the presence of an associated Sjögren's syndrome.

The frequency and nature of pleuropulmonary manifestations in primary biliary cirrhosis (PBC) are poorly documented. The finding of both an interstitial pattern on chest radiographs and a restrictive ventilatory impairment with a gas transfer defect on routine lung function tests in some cases of chronic active hepatitis and PBC has led some authors to suggest that fibrosing alveolitis could be associated with chronic liver disease, ${ }^{12}$ although others have been unable to find such an association. ${ }^{3}{ }^{4}$ Furthermore, PBC is frequently associated with Sjögren's syndrome, an entity in which the interpretation of lung disease remains difficult. ${ }^{5}$ In the present study we have investigated to what extent PBC is associated with pulmonary signs, symptoms, radiological and functional abnormalities and have made comparisons with a healthy control population and with a group of patients affected by the so-called Sicca complex, a limited variant of Sjögren's syndrome.

\section{Methods}

The following categories of patients, matched for sex, age, height, and socioeconomic status were studied: seven with PBC and Sjögren's syndrome, seven with PBC alone, seven with Sicca complex, and 14 normal subjects (table 1). All were non-smokers who gave no history of alcoholism, occupational

Address for reprint requests: Dr Rodriguez-Roisin, Section of Physiology M-023, Department of Medicine, School of Medicine, University of California, San Diego, La Jolla, California 92093, USA.
Table 1 Physical data in groups investigated

\begin{tabular}{|c|c|c|c|}
\hline Category & $\begin{array}{l}\text { Sex } \\
(F / M)\end{array}$ & $\begin{array}{l}\text { Age } \\
(\text { years } \pm S D)\end{array}$ & $\begin{array}{l}\text { Height } \\
(\mathrm{cm} \text { 上SD) }\end{array}$ \\
\hline $\begin{array}{l}\text { Healthy control subjects } \\
(n=14)\end{array}$ & $13 / 1$ & $46.9 \pm 9.4$ & $154 \cdot 6 \pm 4 \cdot 1$ \\
\hline $\begin{array}{l}\text { Primary biliary cirrhosis } \\
\text { (PBC) (overall series) }\end{array}$ & $13 / 1$ & $46 \cdot 3 \pm 10 \cdot 3$ & $154 \cdot 9 \pm 5 \cdot 8$ \\
\hline $\begin{array}{l}\text { PBC without Sjôgren's } \\
\text { Syndrome }(n=7)\end{array}$ & $7 / 0$ & $42 \cdot 9 \pm 10 \cdot 0$ & $153 \cdot 1 \pm 3 \cdot 4$ \\
\hline $\begin{array}{l}\text { PBC with Sjögren's } \\
\text { Syndrome }(n=7)\end{array}$ & $6 / 1$ & $49 \cdot 7 \pm 10 \cdot 0$ & $156 \cdot 5 \pm 7 \cdot 4$ \\
\hline Sicca complex $(n=7)$ & $7 / 0$ & $48 \cdot 7 \pm 7 \cdot 1$ & $152 \cdot 4 \pm 5 \cdot 7$ \\
\hline
\end{tabular}

exposure to dusts known to cause lung damage, cardiopulmonary or autoimmune diseases, or previous medication with potentially fibrogenic drugs.

The diagnosis of PBC was based on clinical and $\rightarrow$ morphological data. All patients had a serum alkaline phosphatase level higher than $300 \mathrm{mU} / \mathrm{ml}$ (normal $\mathrm{N}$ $<85 \mathrm{mU} / \mathrm{ml}$ ) and a positive antimitochondrial antibody test. Eight of them had a serum bilirubin 0 higher than $34 \mu \mathrm{mol} / 1$. According to the liver biopsy $\mathrm{\omega}$ three were stage I, five stage II, five stage III, 알 and one stage IV. The diagnosis of Sicca complex $\bullet$ was accepted when both keratoconjunctivitis and $\mathbb{D}$ xerostomia were present (table 2). The diagnosis of $?$ keratoconjunctivitis was based on the presence of $\frac{T}{\vec{T}}$ clinical symptoms, an abnormal Schirmer's test $\frac{\vec{D}}{\mathbb{D}}$ (wetting of a paper strip $5 \mathrm{~mm}$ or less in $5 \mathrm{~min}$ ) and $\stackrel{\square}{\square}$ Rose bengal ocular staining in the conjunctival sac. ${ }^{6} \stackrel{\Phi}{\complement}$ Xerostomia was recognised by clinical history, by abnormal bilateral parotid gland scintigrams after 
Table 2 Investigation of kertoconjunctivitis and xerostomia

\begin{tabular}{|c|c|c|c|c|c|c|c|}
\hline Cases & $\begin{array}{l}\text { Lacrimal } \\
\text { gland } \\
\text { symptoms }\end{array}$ & $\begin{array}{l}\text { Schirmer's } \\
\text { test }\end{array}$ & $\begin{array}{l}\text { Rose Bengal } \\
\text { stain }\end{array}$ & $\begin{array}{l}\text { Salivary } \\
\text { glands } \\
\text { symptoms }\end{array}$ & $\begin{array}{l}\text { Parotid gland } \\
\text { scintigram }\end{array}$ & $\begin{array}{l}\text { Lip } \\
\text { biopsy }\end{array}$ & - \\
\hline \multicolumn{8}{|c|}{ PBC without Sjögren's syndrome } \\
\hline 1 & - & - & - & - & - & ND & \\
\hline 2 & - & - & - & - & - & ND & \\
\hline 3 & - & - & + & - & - & ND & \\
\hline 4 & - & - & - & - & + & - & \\
\hline 5 & - & - & - & - & - & + & \\
\hline 6 & - & - & - & - & - & ND & \\
\hline 7 & - & - & - & - & - & ND & \\
\hline \multicolumn{8}{|c|}{ PBC with Sjögren's syndrome } \\
\hline 1 & - & - & - & - & + & + & \\
\hline 2 & + & + & + & + & - & NR & \\
\hline 3 & + & - & - & + & - & + & \\
\hline 4 & + & + & - & + & ND & ND & \\
\hline 5 & + & + & + & - & - & + & \\
\hline 6 & + & + & + & - & - & + & \\
\hline 7 & - & + & + & + & + & + & \\
\hline \multicolumn{8}{|c|}{ Sicca complex } \\
\hline 1 & + & - & + & + & + & + & \\
\hline 2 & + & - & + & + & + & + & \\
\hline 3 & + & + & + & + & + & ND & \\
\hline 4 & + & + & + & - & + & + & \\
\hline 5 & + & + & + & + & + & ND & \\
\hline 6 & + & - & + & + & + & + & \\
\hline 7 & + & - & + & + & - & + & \\
\hline
\end{tabular}

$\mathrm{ND}=$ not done $; \mathrm{NR}=$ not reliable $;(-)=$ absent $;(+)=$ present

intravenous administration of $4 \mathrm{mCu}$ of $99 \mathrm{~m} \mathrm{Tc}$ pertechnetate, ${ }^{7}$ and by abnormal lip biopsy. ${ }^{8}$ The diagnosis of both keratoconjunctivitis and xerostomia required the presence of at least two of their respective diagnostic criteria. Sjögren's syndrome was considered to be present when keratoconjunctivitis or xerostomia or both occurred with PBC. ${ }^{5}$ Control subjects were judged to be normal on the basis of negative histories of acute and/or chronic diseases, normal physical examination, and normal chest roentgenograms.

On the day of study each participant was submitted to a modified respiratory questionnaire ${ }^{9}$ and was examined by two chest physicians. Posteroanterior chest radiographs were performed, and each examined and graded independently by five experienced observers according to the 1971 ILO-U/C standard classification. ${ }^{10}$

Lung function studies were performed as follows: (1) arterial $\mathrm{PaO}_{2}$ and $\mathrm{PaCO}_{2}$ (72, Radiometer); (2) thoracic gas volume (Vtg) and airway resistance (Raw) using a constant-volume body plethysmograph (Body-Pneumotest, E Jaeger) ${ }^{11}$, the results being reported as specific airway conductance (sGaw); (3) total lung capacity (TLC) and residual volume (RV) were calculated from Vtg; (4) single-breath transfer factor (TLCO) (Resparameter MK-IV, Morgan) with correction for anaemia ${ }^{12}$ and calculation of transfer coefficient (KCO); (5) Forced vital capacity (FVC), forced expiratory volume in one second $\left(\mathrm{FEV}_{1}\right)$, peak flow (PEF), forced mid-expiratory flow $\left(\dot{\mathrm{V}}_{25-75 \%}\right)$, forced end-expiratory flow $\left(\dot{\mathrm{V}}_{75-85 \%}\right)$, and maximal flow rates at $50 \%$ and $75 \%$ of the FVC $\left(\dot{\mathrm{V}}_{50 \%}\right.$ and $\dot{\mathrm{V}}_{75 \%}$, respectively) (Fleisch pneumotachograph, HP 47304 A); (6) static expiratory compliance of the lung (Cstat) close to functional residual capacity was recorded using an oesophageal latex-balloon and a shutter interrupter ( $E$ Jaeger), according to the method of Milic Emili et al. ${ }^{13}$

The pulmonary function tests (sGaw, Vtg, Dico, static lung volumes, and MEFV curves) were performed on two separate occasions in each control subject and on three occasions in the groups of patients. Arterial blood gases and Cstat (only reliable in 11 out of 14 cases) were measured on two separate occasions in patients with PBC. The data analysed for each participant were the average of two or three values. In each subject lung function studies and clinical and radiological examination were performed on the same day by separate observers and no results were revealed until the study was completed.

Statistical analysis of the results used one-way analysis of variance with a priori contrast, and with Pearson's lineal correlation coefficients.

Written informed consent was obtained from all subjects.

\section{Results}

CLINICAL AND RADIOLOGICAL FEATURES

The pulmonary clinical and radiological characteristics of the patients with PBC and of those with Sicca complex are summarised in table 3. Signs and 
Table 3 Prevalence of abnormal respiratory clinical and radiological features in patients with primary biliary cirrhosis and Sicca complex.

\begin{tabular}{llll}
\hline Features & $\begin{array}{l}\text { PBC } \\
\text { without } \\
\text { Sjögren's } \\
\text { syndrome } \\
(n=7)\end{array}$ & $\begin{array}{l}\text { PBC with } \\
\text { Sjogren's } \\
\text { syndrome } \\
(n=7)\end{array}$ & $\begin{array}{l}\text { Sicca } \\
\text { complex } \\
(n=7)\end{array}$ \\
\hline Cough & 0 & 1 & 4 \\
Sputum & 0 & 1 & 2 \\
Dyspnoea & 0 & 1 & 0 \\
Clubbing & 1 & 2 & 0 \\
Wheezing & 0 & 0 & 0 \\
Crackles & 0 & 0 & 1 \\
Abnormal chest radiograph & 0 & $1 *$ & 0 \\
\hline *Graded 1/10 & 10 &
\end{tabular}

symptoms were uncommon among patients with liver disease alone but were present in four out of the seven with associated Sjögren's syndrome. One patient had mild dyspnoea, another had cough with scanty phlegm, and two others had finger clubbing; one of whom had an abnormal chest film, which was graded $1 / 1$ (ILO-U/C) ${ }^{16}$. Only one patient with PBC but no Sjögren's syndrome showed digital clubbing. Five patients with the Sicca complex had signs and/or symptoms: two had dry cough, two had a slight productive cough, and one had unilateral crackles.

\section{PULMONARY FUNCTION TESTING}

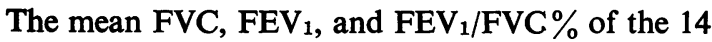
healthy subjects investigated were $106 \%, 95 \%$, and $86 \%$ of their predicted values ${ }^{14}$ respectively; $\mathrm{Vtg}$, TLC, VC, RV, and RV/TLC \% were $119 \%, 111 \%$, $109 \%, 119 \%$, and $108 \%$ of their respective predicted values $^{15}$; Dico and Kco were $114 \%$ and $113 \%$ of their respective predicted values ${ }^{16}{ }^{17}$; and PEF, $\dot{\mathrm{V}}_{25-75 \%}, \dot{\mathrm{V}}_{75-85 \%}, \dot{\mathrm{V}}_{50 \%}$, and $\dot{\mathrm{V}}_{75 \%}$ were $94 \%, 67 \%$, $52 \%, 72 \%$, and $40 \%$, of their predicted values respectively. ${ }^{14} 18$ When these data were compared between the groups studied, no significant differences were found for maximal mid and end-expiratory flow rates, static lung volumes, and sGaw. Static lung compliance and in all but two cases $\mathrm{PaO}_{2}$ and $\mathrm{PaCO}_{2}$ were within predicted normal limits. ${ }^{16}$ Mild hypoxaemia $(10 \mathrm{kPa})$ was observed in two 45 -year-old women with PBC with and without Sjögren's syndrome respectively. No differences in arterial blood gases and Cstat were observed between any patient group.

Mean TLCO was significantly lower both in patients with PBC plus Sjögren's syndrome $(20.5 \pm 1.6 \mathrm{ml}$ $\mathrm{min}^{-1} \mathrm{mmHg}$ ) and in patients with Sicca complex $\left(20 \cdot 4 \pm 1 \cdot 1 \mathrm{ml} \mathrm{min}^{-1} \mathrm{mmHg}^{-1}\right)$, than in controls

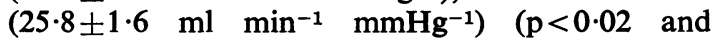
$\mathrm{p}<0.016$, respectively). Mean TLCo in PBC patients without Sjögren's syndrome, $\left(24 \cdot 7 \pm 0.6 \mathrm{ml} \mathrm{min}^{-1}\right.$ $\mathrm{mmHg}^{-1}$ ) was normal. Mean Kco was also significantly lower in patients with PBC plus Sjögren's syndrome $\left(5 \cdot 3 \pm 0.4 \mathrm{~min}^{-1} \mathrm{mmHg}^{-1}\right)$ than in those without it $\left(6.4 \pm 0.3 \mathrm{~min}^{-1} \mathrm{mmHg}^{-1}\right)$, but mean $\mathrm{KcO}$ did not differ significantly from controls in either of these groups.

\section{Discussion}

The first account of a clinical association between lung fibrosis and PBC was given by Mason et al in 1970, Turner-Warwick ${ }^{1}$ having previously drawn attention to the association of pulmonary fibrosis with other chronic liver diseases. Later Golding et al $^{19}$ added further observations and reported the presence of gas transfer defects, with either an abnormal chest film or a restrictive ventilatory impairment, in $\infty$ several patients with chronic liver disease including PBC. However in two patients with PBC who came to necropsy Stanley et $a l^{3}$ found widespread intrapulmonary granulomas without fibrosis, one subject having an interstitial radiographic pattern and an impairment of the transfer factor.

The present study suggests that the incidence of clinical, radiographic and functional abnormalities is very low and that when present it may be related to the existence of an associated Sjögren's syndrome. Only four out of 14 patients with PBC had one or more clinical and/or radiological manifestations of pulmonary disease and all had keratoconjunctivitis sicca, xerostomia or both. Digital clubbing was observed in one patient with PBC not associated with Sjögren's syndrome but this feature cannot be related specifically to pulmonary disease.

The only consistently abnormal lung function finding was the reduction of gas transfer factor which was observed in patients with PBC associated with Sjögren's syndrome and in patients with the Sicca complex. These data suggest that the development of an abnormal diffusing capacity in patients with PBC, is somehow related to an associated Sjögren's syndrome and not to liver disease itself.

Comparisons of the results of the present investigation with previous reports cannot be made because of differences in format and because in papers $N$ previously reporting an association between $\mathrm{PBC}$ and $N$ lung fibrosis it has not been stated that factors noxious to the lung such as tobacco, alcohol, occupational or nonoccupational exposure to dust, associated clinical 2 conditions, and iatrogenic factors have been excluded. $\stackrel{\varrho}{\subseteq}$ Furthermore the presence of an associated Sicca $\stackrel{D}{\mathscr{D}}$ complex, to which pulmonary impairment may be + related, has not been investigated previously. Recently Clarke et $\mathrm{l}^{20}$ have reported a high incidence $\overrightarrow{\mathbb{D}}$ of mild scleroderma in a series of patients with PBC $\stackrel{\odot}{\vec{D}}$ in some of whom respiratory functional abnormali- $\stackrel{\mathbb{\perp}}{\square}$ ties, such as gas transfer impairment and airway obstruction were detected. 
A wide range of pulmonary abnormalities has been reported in patients with the Sicca complex, either in isolation or in association with a connective tissue disorder - that is, Sjögren's syndrome. ${ }^{5}$ Some of these are purely morphological, such as lymphocytic and plasma cell infiltration of the trachea and the large and small airways. Others have clinical relevance-for example, diminished mucous secretions caused by bronchial mucous gland destruction in large airways, bronchopulmonary infections related to dryness of the respiratory tract, pleural effusions, fibrosing alveolitis of both the mural and desquamative types, and lymphocytic interstitial pneumonitis.

In a few pulmonary function studies of patients suffering from different connective tissue disorders, the existence of a gas transfer defect with or without ventilatory impairment has been noted in some patients with Sjögren's syndrome. ${ }^{21-23}$ In a series of patients with the Sicca complex, studied by Newball and Brahim, ${ }^{24}$ almost one-half had small airways dysfunction unassociated with chronic obstructive lung disease.

However, most of these studies failed to exclude a number of factors which could have contributed to the development of lung disturbances, particularly those clinical conditions chiefly related to chronic liver disease such as renal failure, fluid retention, or hepatic encephalopathy, or those connective tissue disorders which are frequently associated with Sjögren's syndrome and have a fairly high prevalence of pleuropulmonary manifestations such as rheumatoid arthritis and systemic lupus erythematosus.

In our study mean TLCo was significantly lower only in patients with the Sicca complex and in those with PBC associated with Sjögren's syndrome. No differences were observed in any other parameter of lung function, except for hypoxemia in two patients and a difference in mean Kco between PBC patients with and without Sjögren's syndrome, the interpretation of which is uncertain. Maximal and midexpiratory flow rates, considered to be a sensitive test for early detection of small airway dysfunction, were mostly below $70 \%$ of their respective predicted values in all groups studied, including the control group. Although the discriminant value of these measurements is still controversial, ${ }^{25}$ it is possible that exposure to industrial or urban pollutants, ${ }^{26}$ or the influence of hitherto unidentified environmental factors, could be the cause of these mild respiratory functional abnormalities.

Although any conclusion concerning cause and mechanism is premature, the presence of a gas transfer defect in Sjögren's syndrome might represent a response to a variety of respiratory injuries. The absence of any significant ventilatory impairment in our series and its presence in patients studied by others would suggest that Sjögren's syndrome is a progressive disorder with a wide spectrum of pulmonary functional abnormalities.

In conclusion, it appears that the clinical, physiological, and radiographic manifestations of pulmonary disease observed in patients with PBC are the result of an associated connective tissue disorder, such as Sjögren's syndrome, rather than the result of PBC per se.

We are indebted to Professor C Rozman, Dr J Sanchis-Aldas, and Dr E Ros, for suggestions in the preparation of the manuscript, and to Mrs C Gistau and G Godoy, respiratory physiology technicians, for their assistance.

\section{References}

1 Turner-Warwick M. Fibrosing alveolitis and chronic liver disease. $Q J$ Med 1968; 37:133-49.

2 Mason AMS, McIllMurray MB, Golding PL, Hughes, DTD. Fibrosing alveolitis associated with renal tubular acidosis. Br Med J 1970; 4:596-9.

3 Stanley NN, Woodgate DJ. Mottled chest radiograph and gas transfer defect in chronic liver disease. Thorax 1972; 27:315-23.

4 Stanley NN, Williams AJ, Dewar CA, Blendis, LM, Reid L. Hypoxia and hydrothoraces in a case of liver cirrhosis: correlation of physiological, radiographic, scintigraphic, and pathological findings. Thorax $1977 ; 32: 457-71$.

5 Shearn MA. Sjögren's syndrome. Philadelphia: WB Saunders, 1971: 9-234.

6 Holm S. Keratoconjunctivitis sicca and the sicca syndrome. Acta Ophthalmol 1949; Suppl no 33.

7 Schall GL, Anderson LG, Wolf RO et al. Xerostomia in Sjögren's syndrome. Evaluation by sequential salivary scintigraphy. JAMA 1971; 216: 2109-16.

8 Chisholm DM, Mason DK. Labial salivary gland biopsy in Söjgren's syndrome. J Clin Pathol 1968; 21:656-60.

9 Medical Research Council. Standardized Questionnaire on Respiratory Symptoms. Br Med J 1960; 2: 1665 .

10 ILO/UC International Classification of Radiographs of Pneumoconioses, 1971 (no 22 revised): Occupational Safety and Health Series. Geneva: International Labour Office, 1972

11 Dubois AB, Botelho SY, Comroe JH Jr. A new method for measuring airway resistance in man using a body plethysmograph: values in normal subjects and in patients with respiratory diseases. $J$ Clin Invest 1956; 35:327-35.

12 Cotes JE, Dabbs JM, Elwood PC, Hall, AM, McDonald, A, Saunders, MJ. Iron-deficiency anaemia: its effect on transfer factor for the lung (diffusing capacity) and ventilation and cardiac frequency during submaximal exercise. Clin Sci 1972. 42: 325-35. 
13 Milic-Emili J, Mead J, Turner JM, Glauser, EM. Improved technique for estimating pleural pressure from esophageal balloons. J Appl Physiol 1964; 19: 207-11.

14 Knudson RJ, Slatin RC, Lebowitz MD, Burrows, B. The maximal expiratory flow-volume curve. Normal standards, variability, and effects of age. Am Rev Respir Dis 1976; 113:587-600.

15 Goldman HI, Becklake MR. Respiratory function tests: Values at median altitudes and the prediction of normal results. Am Rev Tuberc 1959; 79:457-67.

16 Cotes JE. Lung function at different stages in life, including reference values in lung function, assessment and application in medicine. Third edition. Oxford: Blackwell Scientific, 1975: 340-395.

17 Billiet L, Baisier W, Naedts JP. Effect de la taille, du sexe et de l'age sur la capacité de diffusion pulmonaire de l'adulte normal. J Physiol (Paris) 1963: 55: 199-200.

18 Morris JF, Koski A, Breese JD. Normal values and evaluation of forced end-expiratory flow. Am Rev Respir Dis 1975; 111:755-62.
19 Golding PL, Smith M. Williams R. Multisystem involvement in chronic liver diseases. Am J Med 1973; 55:772-82.

20 Clarke AK, Galbraith RM, Hamilton EBD, Williams R. Rheumatic disorders in primary biliary cirrhosis. Ann Rheum Dis 1978; 37:42-7.

21 Catterall M, Rowel NR: Respiratory function studies in patients with certain connective tissue diseases. Br J Dermatol 1965; 77:221-5.

22 Massachusetts General Hospital: Case Records, no. 28-1975. $N$ Engl J Med 1975; 293:136-44.

23 Strimlan CV, Rosenow EC, Divertie MB, Harrison, EG.Pulmonary manifestations of Sjögren's syndrome. Chest 1976; 70:354-61.

24 Newball HH, Brahim SA. Chronic obstructive airway disease in patients with Sjögren's syndrome. Am Rev Respir Dis 1977; 115:295-304.

25 Sobol BJ. The early detection of airway obstruction: another perspective. Am J Med 1976; 60:619-24.

26 White JR, Froeb HF. Small-airways dysfunction in non-smokers chronically exposed to tobacco smoke. $N$ Engl J Med 1980; 302:720-3. 